\title{
ADAPTAÇÃO DE ESPÉCIES ARBÓREAS NATIVAS EM UM SISTEMA AGROSSILVICULTURAL, SUBMETIDAS A EXTREMOS CLIMÁTICOS DE GEADA NA REGIÃO DE FLORIANÓPOLIS ${ }^{1}$
}

\author{
Ana Rita Rodrigues Vieira ${ }^{2}$, Diogo Feistauer ${ }^{3}$ e Vanderley Porfírio da Silva ${ }^{4}$
}

\begin{abstract}
RESUMO - O principal objetivo deste trabalho foi avaliar a resposta de cinco espécies arbóreas nativas submetidas a extremos climáticos de geada em um sistema agroflorestal, na região de Florianópolis, Santa Catarina (latitude de $27^{\circ} 35^{\prime} \mathrm{S}$, longitude 483' W e altitude de 1,84 m). O solo é do tipo Neossolo quartzarênico hidromórfico distrófico, textura arenosa, com elevada flutuação do lençol freático. Foram tomadas sete parcelas de dez árvores, seguindo o delineamento estatístico inteiramente casualizado. Os parâmetros analisados foram altura total, número de folhas, incremento médio em altura total e número de folhas de cada árvore (quantificados a cada quatro meses), porcentagem de árvores com folhas danificadas pela geada e sobrevivência de cada planta após a geada. Os parâmetros estatísticos analisados foram a média e o desvio-padrão. Para analisar os resultados utilizou-se o teste de Tukey, a 5\% de probabilidade. Os ingás (Inga uruguensis e Inga sessilis) apresentaram tolerância à geada e um alto potencial para implantação em SAFs nas condições edafoclimáticas em estudo. A espécie tucaneira (Citharexylium myrianthum) apresentou pouca tolerância à geada, porém mostrou alta taxa de rebrota. As espécies corticeira (Erythrina falcata), olandi (Calophyllum brasilienses) e licurana (Hieronyma alchorneoides) apresentaram alta mortalidade em razão da geada, não se mostrando indicadas para compor um SAF na região em estudo.
\end{abstract}

Palavras-chaves: Sistema agroflorestal, geada e seleção de espécies.

\section{ADAPTATION OF NATIVE TREE SPECIES SUBMITTED TO EXTREME FROST STRESS UNDER AN AGROSILVICULTURAL SYSTEM IN THE FLORIANOPOLIS REGION}

\begin{abstract}
This work aimed to evaluate the response of five indigenous arboreal species, submitted to extreme frost stress in an agroforest system (AFS) in Florianópolis, Santa Catarina (lat. 27 $35^{\prime} S$, long. 48 $34^{\prime} \mathrm{W}$ and alt. of 1,84 m). The soil is a distrophic Hydromorphic Quartzarenic Neosoil, with sandy texture, and high watertable flotation.The experiment was arranged in a randomized complete design, with seven plots of ten trees each. The analyzed parameters were: height, number of leaves, average height increase and number of leaves of each tree, measured every four months, percentage of burned leaves and rate of survival of the plants after frost. The statistical parameters analyzed were: average and standard deviation.The Tukey test at 5\% probability was used to analyze the results. The ingás (Inga uruguensis and Inga sessilis) showed tolerance to frost and a high potential for AFS, under the edafo-climatic conditions studied. The species tucaneira (Citharexylum myrianthum) did not show good tolerance to frost but it did show a high resprouting rate. The species corticeira (Erythrina falcata), olandi (Calophyllum brasiliense) and licurana (Hieronyma alchorneoides) showed a high mortality rate under frost, but it did not show a good potential for AFS under the edafo-climatic conditions studied.
\end{abstract}

Key words: $\quad$ Agroforest system, frost and species selection.

1 Recebido para publicação em 29.1.2002.

Aceito para publicação em 9.9.2003.

2 Prof. Adjunto, Dra., do Dep. de Fitotecnia da Universidade Federal de Santa Catarina - UFSC, Rod. Ademar Gonzaga 1340, 88040-900 Florianópolis-SC, <arvieira@ mbox1.ufsc.br>; ${ }^{3}$ Estudante, Bolsista PIBICC-CNPQ, graduando do curso de Agronomia - UFSC, <dfeistauer@yahoo.com.br>. ${ }^{4}$ Eng.-Agr., M.S. em Agroecossistemas, técnico da EMATER-Paraná, $<$ pmadeira@pr.gov.br>. 


\section{INTRODUÇÃO}

O Brasil possui a maior diversidade vegetal do mundo. A falta de direcionamento técnico e de conscientização ecológica na exploração de nossos recursos florestais tem acarretado prejuízos irreparáveis e espécies de grande valor ecológico estão em vias de extinção (Lorenzi, 1998).

São muitas as necessidades e justificativas para o reflorestamento, especialmente com árvores de uso múltiplo em monocultivo ou em sistemas agroflorestais, as quais variam de acordo com as características ambientais e socioeconômicas de cada região. A presença de árvores favorece os sistemas de produção agroflorestais em aspectos como a manutenção da ciclagem de nutrientes e o aumento na diversidade de espécies (Franke et al., 2000).

MacDicken \& Vergara (1990) e Young (1994) denominam sistemas agroflorestais (SAFs), genericamente, os sistemas produtivos que incluem árvores em consórcio e, ou, associação com culturas agrícolas e, ou, com criação de animais. Estes sistemas são apontados como opções preferenciais de uso da terra pelo seu alto potencial de aumentar o nível de rendimento em relação a aspectos agronômicos, sociais, econômicos e ecológicos.

A implantação de sistemas silvipastoris tem permitido o aumento da capacidade de suporte das pastagens, a conservação do solo e da água e a oferta de produtos madeiráveis. Outro benefício ocasionado pela presença das árvores é a manutenção da pastagem verde mesmo durante o inverno, após a ocorrência de geadas. Para Porfírio da Silva \& Mazuchowski (1999), estes fatos estão motivando a transformação de pastagens puras em sistemas associados à produção de madeira e de outros produtos florestais.

Nos sistemas silvipastoris e, ou, agrossilviculturais verificam-se a mitigação de extremos climáticos e o aumento na produção total/área, que são conseqüências do microclima e das interações entre os componentes do sistema. As árvores modificam o ambiente, o que o torna mais estável, modifica os picos térmicos (máximos e mínimos), altera o comportamento animal e melhora sua eficiência, obtendo-se melhor produção (Young, 1994).

A queda gradual da produtividade das culturas anuais e, ou, perenes, reflexo da perda de fertilidade do solo gerada pelo declínio de matéria orgânica e pela deficiência de ciclagem de nutrientes no solo, tem se

R. Árvore, Viçosa-MG, v.27, n.5, p.627-634, 2003 tornado evidente nos sistemas de agricultura tradicional. A utilização de espécies nativas, principalmente leguminosas arbóreas ou arbustivas, como forma de melhorar a fertilidade natural dos solos tem sido uma prática bastante comum nas regiões tropicais, destinadas à produção de alimentos básicos (Magalhães et al., 2000).

Por outro lado, apesar dos benefícios que os sistemas agroflorestais podem trazer, pouco se sabe sobre a magnitude das modificações microclimáticas e das respostas ecofisiológicas das espécies arbóreas e das culturas agrícolas e, ou, pastagens decorrentes de sua implantação (Sá, 1994).

Entende-se, portanto, que a falta de informações geradas pela pesquisa sobre as possibilidades de implantação do sistema agroflorestal em regiões frias, como é o caso de algumas regiões do Paraná e dos Estados de Santa Catarina e Rio Grande do Sul, acarreta dificuldades na avaliação do desempenho das espécies arbóreas e, conseqüentemente, na implantação de sistemas agroflorestais como opções de uso da terra.

O zoneamento agroecológico para espécies arbóreas nativas para o Estado de Santa Catarina retrata bem essas dificuldades, quando aponta somente os dados de temperaturas mínimas limitantes do ar e o número de geadas suportáveis, juntamente com precipitação pluviométrica e déficit hídrico nas áreas de ocorrência, e não nas áreas de plantio das espécies, o que mostra que essas informações não são baseadas em experimentação, ou seja, avaliação de desempenho dessas espécies (Carvalho, 1994).

Diante disso, o objetivo principal do presente trabalho foi avaliar as respostas das espécies arbóreas nativas com potencial para implantação em um sistema agrossilvicultural, em areias quartzosas, na região de Florianópolis, submetidas a eventos climáticos extremos de geadas.

\section{MATERIAL E MÉTODOS}

A unidade de sistema agroflorestal, objeto de avaliações, foi implantada na fazenda Ressacada, de propriedade do CCA/UFSC, no município de Florianópolis-SC (latitude de $27^{\circ} 35^{\prime} \mathrm{S}$, longitude $48^{\circ} 34^{\prime}$ W e altitude de $1,84 \mathrm{~m}$ ). O clima da região é Cfa, segundo a classificação climática de Köppen. O solo é do tipo Neossolo quartzarênico hidromórfico (areia quartzosa hidromórfica distrófica), textura arenosa, pouco desenvolvido, com transição do horizonte A para C, ou seja, 
um solo de elevada flutuação de lençol freático e pobre em nutrientes disponíveis Quadro 1.

Estudou-se um sistema agrossilvicultural (culturas agrícolas + árvores) em uma área aproximada de 1,3 ha. Plantaram-se árvores de diversas espécies, todas nativas da região, em linhas simples, no sentido diagonal aos ventos sul e nordeste, que são os ventos predominantes e de maiores intensidades na área. Utilizou-se o espaçamento de 1,5 a 2,5 m entre árvores e $14 \mathrm{~m}$ entre as linhas de árvores.

O plantio foi realizado em 22 de outubro de 1999, sendo plantadas, em seqüência nas linhas, as seguintes espécies: tucaneira (Citharexylum myrianthum Cham.), corticeira (Erythrina falcata Benth.), olandi (Calophyllum brasiliense Cambess.), ingá (Inga uruguensis Hook. \& Am. e Inga sessilis Mart.) e licurana (Hieronyma alchorneoides Allemão).

Nas linhas entre as árvores, em 20 parcelas de $2 \mathrm{~m}^{2}$ cada, foram plantadas culturas agrícolas anuais de feijãopreto (Phaselosus vulgaris L., variedade. Rio Tibagi), em consórcio com o milho (Zea mays, variedade comercial AG 1051). O sistema de cultivo adotado para as culturas anuais foi o plantio direto, tendo sido usada como cultura de cobertura a aveia-preta (Avena sativa L.). $\mathrm{O}$ cultivo das culturas agrícolas teve como objetivo favorecer possíveis retornos econômicos ao produtor, durante o estádio inicial de desenvolvimento das árvores.

Para avaliação ambiental das árvores nativas foram utilizados os seguintes parâmetros: altura total e número de folhas de cada planta (medidas a cada quatro meses), incremento médio de altura total e do número de folhas de cada planta e porcentagem de sobrevivência das árvores após a geada ocorrida no mês de julho de 2000 .
O incremento médio de altura total e do número de folhas foi calculado segundo a fórmula:

$$
I N C=\frac{(L a t-L a n)}{L i}
$$

em que $I N C=$ incremento; $L a t=$ avaliação feita no período; $L a n=$ avaliação feita no período anterior; e $L i$ = avaliação inicial ou primeira.

Os dados foram coletados em sete parcelas de dez árvores cada, escolhidas aleatoriamente. Adotou-se o delineamento estatístico inteiramente casualizado. Foram calculados a média e o desvio-padrão de cada espécie, nos diferentes períodos de avaliação. A comparação das médias foi feita pelo teste de Tukey, a 5\% de probabilidade.

Os dados de temperatura mínima do ar foram coletados no abrigo meteorológico da Estação Meteorológica do Aeroporto Internacional Hercílio Luz, localizada ao lado da fazenda Ressacada.

\section{RESULTADOS E DISCUSSÃO}

De acordo com Silva (2000), a diferença de temperatura mínima do ar entre o abrigo meteorológico e a relva varia de -2 a $-5{ }^{\circ} \mathrm{C}$, segundo avaliações feitas em diferentes localidades do Estado de Santa Catarina.

Constatou-se (Quadro 2) que as temperaturas mínimas do ar no abrigo meteorológico foram iguais ou inferiores a $2,5^{\circ} \mathrm{C}$. Portanto, de acordo com Silva (2000), estes dados indicam que, na relva, a temperatura mínima deve ter atingido valores iguais ou inferiores a $0,5^{\circ} \mathrm{C}$, situação esta que caracteriza condição de geada. Neste sentido, segundos os dados coletados na estação

Quadro 1 - Análise da fertilidade do solo da área a $10 \mathrm{~cm}$ de profundidade Table 1 - Soil fertility analysis of the area at $10 \mathrm{~cm}$ depth

\begin{tabular}{|c|c|c|c|c|c|c|c|c|c|c|c|c|}
\hline \multirow{2}{*}{$\begin{array}{c}\text { Textura } \% \\
\text { ARG. }\end{array}$} & \multirow{2}{*}{$\mathrm{pH}$} & \multirow{2}{*}{$\begin{array}{l}\text { IND. } \\
\text { SMP* }\end{array}$} & $\mathrm{P}$ & $\mathrm{K}$ & MO & $\mathrm{AL}$ & $\mathrm{Ca}$ & $\mathrm{Mg}$ & \multirow{2}{*}{$\frac{\mathrm{Na}}{(\mathrm{ppm})}$} & $\mathrm{H}+\mathrm{AL}$ & $\mathrm{S}$ & CTC \\
\hline & & & \multicolumn{2}{|c|}{ (ppm) } & $(\%)$ & \multicolumn{3}{|c|}{$(\mathrm{cmolc} / \mathrm{l})$} & & \multicolumn{3}{|c|}{$(\mathrm{cmolc} / \mathrm{l})$} \\
\hline 13 & 4,2 & 5,0 & 50 & 112 & 8,6 & 2,4 & 1,5 & 0,3 & 15 & 8,79 & 2,15 & 10,94 \\
\hline B & MB & & A & S & A & & B & B & & & B & A \\
\hline
\end{tabular}

$\mathrm{MB}=$ muito baixa, $\mathrm{B}=$ baixa, $\mathrm{S}=$ suficiente e $\mathrm{A}=$ alta.

* a solução SMP representa a medida do pH na solução tamponada do solo, o que mostra a acidez potencial do solo, tornando-se referência para estabelecer a quantidade de calcário a ser aplicada no solo. 
meteorológica, ocorreram seis dias de geada no período avaliado.

Quadro 2 - Dias de ocorrência de geada e dados de temperatura mínima do ar no abrigo meteorológico da estação meteorológica do Aeroporto Hercílio Luz

Table 2 - Frost occurrence days and minimum temperature data at the weather station at Hercilio Luz airport

\begin{tabular}{|c|c|}
\hline Dia & Temperatura Mínima do $\operatorname{Ar}\left({ }^{\circ} \mathrm{C}\right)$ \\
\hline $14 / 7 / 2001$ & 2,0 \\
\hline $17 / 7 / 2001$ & 1,2 \\
\hline $18 / 7 / 2001$ & 2,4 \\
\hline $20 / 7 / 2001$ & 1,7 \\
\hline $24 / 7 / 2001$ & 2,5 \\
\hline $25 / 7 / 2001$ & 2,4 \\
\hline
\end{tabular}

Constata-se (Quadro 3) que os ingás (Inga uruguensis e Inga sessilis) apresentaram, no primeiro ano de avaliação, $46 \%$ das árvores com folhas danificadas pela geada, porém mostraram alta capacidade de rebrota $(95 \%)$ e, por sua vez, baixa mortalidade de plantas. Por outro lado, a licurana (Hieronyma alchorneoides), a tucaneira (Citharexylum sp.), a corticeira (Erythrina falcata) e o olandi (Calophyllum brasiliense) apresentaram $100 \%$ das árvores com folhas danificadas pela geada. A licurana e o olandi apresentaram baixa capacidade de rebrota após a geada (respectivamente, 6 e $14 \%)$, mostrando uma taxa de mortalidade próxima dos $100 \%$. A corticeira, apesar de também ter $100 \%$ das árvores com as folhas danificadas pela geada, mostrou um comportamento um pouco superior ao das duas últimas, com uma taxa de rebrota de $48 \%$ e sobrevivência de $35 \%$. A tucaneira apresentou, junto com o ingá, alta capacidade de rebrota (77\%), vindo a alcançar uma porcentagem de sobrevivência de $76 \%$, mesmo tendo $100 \%$ das plantas com folhas danificadas pela geada.

Também, pode-se concluir com base nos dados do Quadro 3 que nenhuma planta foi totalmente tolerante ao frio. O olandi não suporta geadas, pois apresentou $100 \%$ das árvores com folhas danificadas e taxas de sobrevivência e de rebrota baixas, que foram, respectivamente, de 12 e $14 \%$, o que explica a sua grande mortalidade. A tucaneira e o ingá, apesar de suportarem um menor número de geadas por ano do que a corticeira (até 5 e até 18 , respectivamente), apresentaram, em relação a esta, maior porcentagem de sobrevivência (76 e 94\%, respectivamente, contra $35 \%$ de porcentagem de sobrevivência da corticeira) e capacidade de rebrota de 95 e $77 \%$, respectivamente, contra $48 \%$ de capacidade de rebrota da corticeira, o que não está em consonância com as referências bibliográficas, muito embora seja necessário ressaltar que a corticeira é uma espécie secundária tardia que, tanto no estádio de plântula como de plantas jovens, se encontra sob a proteção das demais vegetações. A licurana, dentre as espécies analisadas, foi a que mostrou maior mortalidade em uma situação de estresse ambiental como a geada.

As Figuras 1 e 2 mostram o desempenho das árvores no local, através dos parâmetros altura e número de folhas.

Constata-se nas Figuras 1 e 2 que o ingá e a tucaneira apresentaram um aumento constante tanto da altura total quanto do número de folhas em todos os períodos de avaliação, mesmo quando submetidas ao estresse ambiental de seis dias de geada, fenômeno bastante adverso na região. Por outro lado, as espécies corticeira (Erythrina

Quadro 3 - Dados ecológicos das árvores na área agrossilvicultural Table 3 - Ecological data of the agrosilvicultural area trees

\begin{tabular}{|c|c|c|c|c|c|c|c|}
\hline \multirow[b]{2}{*}{ Planta } & \multicolumn{4}{|c|}{ Dados de Literatura } & \multicolumn{3}{|c|}{ Dados do Experimento } \\
\hline & $\begin{array}{l}\text { Estágio } \\
\text { sucessional }\end{array}$ & $\begin{array}{c}\text { Temp. } \\
\text { mês mais frio } \\
\left({ }^{\circ} \mathrm{C}\right)\end{array}$ & $\begin{array}{c}\text { Tolerante } \\
\text { ao frio }\end{array}$ & $\begin{array}{c}\mathrm{N}^{\mathrm{o}} \text { geadas } \\
\text { suportadas por } \\
\text { ano }\end{array}$ & $\begin{array}{c}\text { Média da \% de árvores } \\
\text { com folhas danificadas } \\
\text { pela geada }\end{array}$ & $\begin{array}{l}\text { Taxa de rebrota } \\
(\%) \text { após a geada }\end{array}$ & $\begin{array}{c}\text { Taxa } \\
\text { sobrevivência } \\
\text { após a geada }(\%)\end{array}$ \\
\hline Ingá & Secundária inicial & 13 a 18 & Não & Até 18 & 46 & 95 & 94 \\
\hline Tucaneira & Secundária & 12 a 22 & Não & Até 5 & 100 & 77 & 76 \\
\hline Corticeira & Secundária tardia & 12 a 18 & Não & Até 33 & 100 & 48 & 35 \\
\hline Olandi & Clímax & 16 a 25 & Não & Ausentes ou raras & 100 & 14 & 12 \\
\hline Licurana & Secundária & $*$ & $*$ & $*$ & 100 & 6 & 5 \\
\hline
\end{tabular}

Fonte: Adaptada de Carvalho (1994); e * dados não encontrados na literatura. 


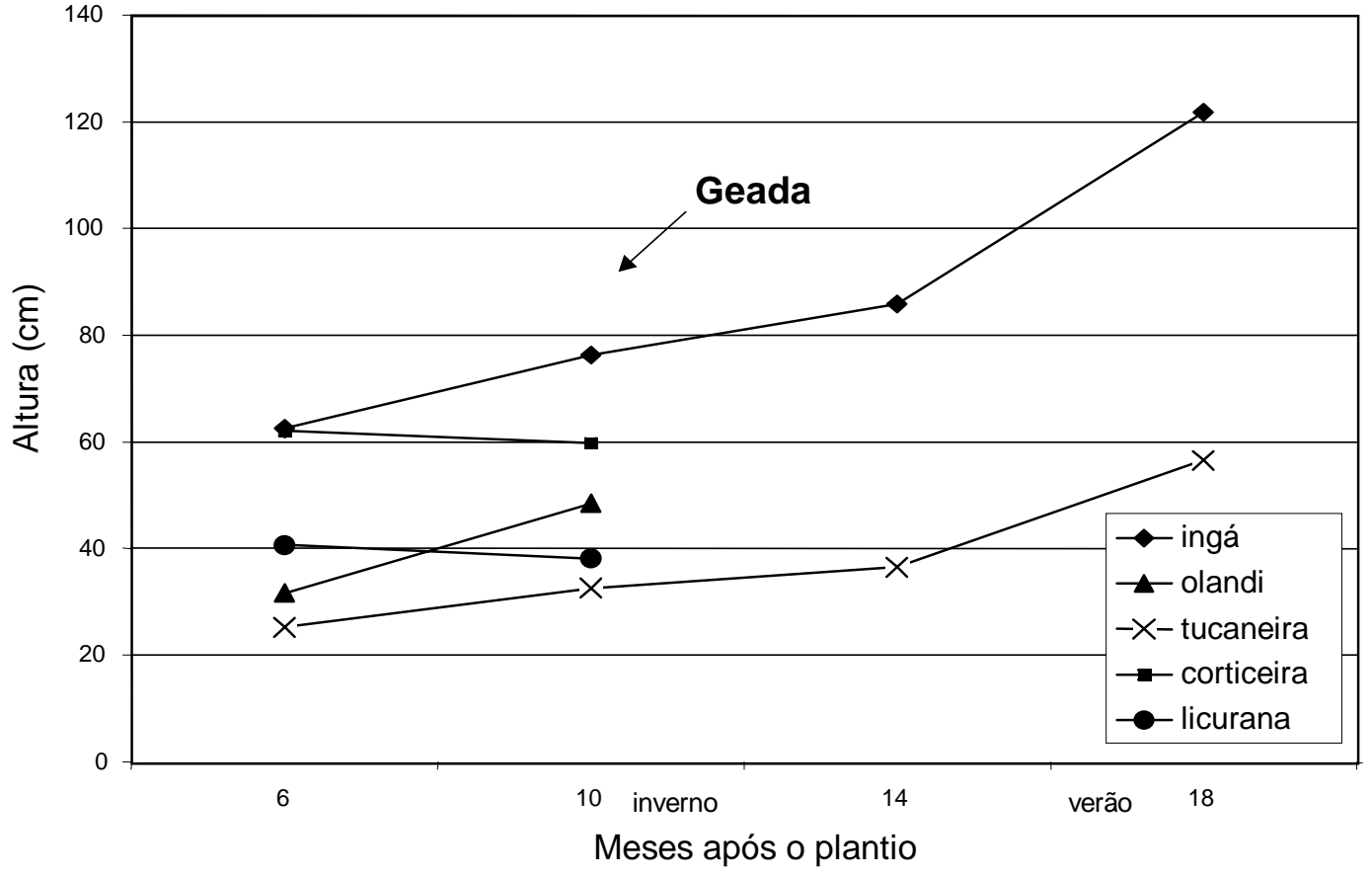

Figura 1 - Altura média das espécies arbóreas nos diferentes períodos de avaliação.

Figure 1-Average height of the tree species under different evaluation periods.

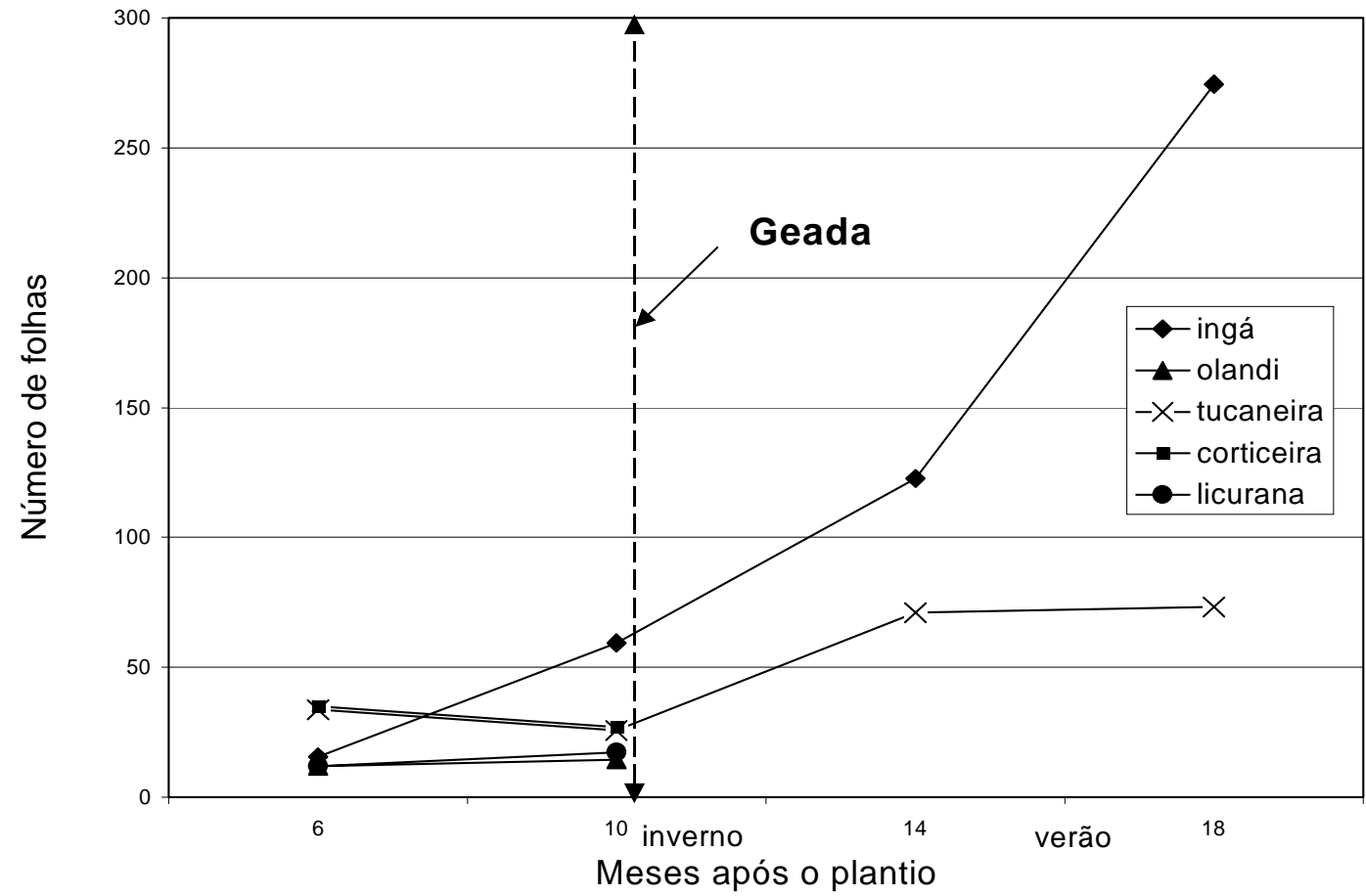

Figura 2 - Média do número de folhas das árvores nos diferentes períodos de avaliação.

Figure 2 -Average of number of leaves of the trees under different evaluation periods. 
falcata), licurana (Hieronyma alchorneoides) e olandi (Calophyllum brasiliense) apresentaram os menores parâmetros de desenvolvimento e tolerância à geada.

Deve-se ressaltar que esse comportamento com relação à geada baseia-se na tolerância de cada planta à formação de cristais de gelo no seu interior e à severa desidratação das células que ocorre com a formação dos cristais de gelo nos espaços extracelulares das células (Salisbury \& Ross, 1994). Assim, é de se supor que existam diferenças morfológicas e fisiológicas entre estas espécies no que tange à sua capacidade de tolerância à geada.

As análises estatísticas descritas nos Quadros 4, 5 e 6 procuram retratar as diferenças de comportamento entre as árvores avaliadas, conforme descrevem as Figuras 1 e 2 .

Conforme o Quadro 4, os valores mais altos dos desvios-padrão ocorreram em função da alta variabilidade dos dados entre plantas da mesma espécie, o que é uma funcão da fisiologia bastante diferenciada de cada espécie arbórea e da idade diferencida das plantas no plantio e replantio. A tucaneira, por exemplo, é uma espécie caducifólia, enquanto as demais não o são. Somado a isto, a análise estatística aplicada comparou o conjunto das espécies, o que significa que houve uma comparação implícita das suas fisiologias de crescimento e desenvolvimento, as quais são diferentes. Essas diferenças podem ser evidenciadas pela altura total e pelo número de folhas, bem como pelo incremento de altura total e número de folhas descritos nos Quadros 5, 6 e 7.

Quadro 5 - Incremento de altura total e de número de folhas das espécies referente aos diferentes períodos de avaliação

Table 5 - Increase of total height and number of leaves of the trees under different evaluation periods

\begin{tabular}{|c|c|c|}
\hline \multicolumn{3}{|c|}{ Incremento } \\
\hline Espécie & Altura total $(\mathrm{cm})$ & Número de folhas \\
\hline Corticeira & $0,4708 \mathrm{~A}$ & $0,0730 \mathrm{~A}$ \\
\hline Licurana & $-0,0291 \mathrm{~A}$ & $0,1675 \mathrm{~A}$ \\
\hline Tucaneira & $-0,0142 \mathrm{~A}$ & $0,1700 \mathrm{~A}$ \\
\hline Olandi & $0,4270 \mathrm{~A}$ & $0,4270 \mathrm{AB}$ \\
\hline Ingá & $0,1150 \mathrm{~A}$ & $1,9774 \mathrm{~B}$ \\
\hline
\end{tabular}

OBS: Médias seguidas da mesma letra não diferem entre si, na vertical, pelo teste de Tukey, a 5\%.

Quadro 4 - Média e desvio-padrão das espécies árbóreas avaliadas nos diferentes períodos de avaliação Table 4 -Average and standard deviation of the tree species evaluated under different evaluation periods

\begin{tabular}{|c|c|c|c|c|}
\hline \multirow{3}{*}{ Espécie } & \multicolumn{4}{|c|}{ Data } \\
\hline & $\begin{array}{c}23 / 03 / 00 \\
(5 \text { meses })\end{array}$ & $\begin{array}{c}27 / 06 / 00 \\
(9 \text { meses })\end{array}$ & $\begin{array}{c}11 / 11 / 00 \\
(14 \text { meses })\end{array}$ & $\begin{array}{c}02 / 03 / 01 \\
(18 \text { meses })\end{array}$ \\
\hline & Média/DP & Méd./ DP & Méd./ DP & Méd./ DP \\
\hline \multicolumn{5}{|c|}{ Altura Total $(\mathrm{cm})$} \\
\hline Ingá & $60,1 \pm 17,1$ & $76,2 \pm 19,6$ & $85,8 \pm 20,4$ & $121,7 \pm 32,8$ \\
\hline Tucaneira & $23,5 \pm 9,9$ & $32,4 \pm 10,9$ & $35,3 \pm 12,2$ & $56,4 \pm 29,9$ \\
\hline Corticeira & $62,0 \pm 6,9$ & $59,7 \pm 13,7$ & $*$ & $*$ \\
\hline Olandi & $31,6 \pm 9,9$ & $48,4 \pm 15,9$ & $*$ & $*$ \\
\hline Licurana & $40,6 \pm 20,6$ & $38,1 \pm 16,5$ & $*$ & $*$ \\
\hline \multicolumn{5}{|c|}{ Número de Folhas } \\
\hline$\overline{\text { Ingá }}$ & $15,7 \pm 15,2$ & $38,1 \pm 19,6$ & $71,4 \pm 26,1$ & $269,0 \pm 126,7$ \\
\hline Tucaneira & $25,6 \pm 14,0$ & $32,8 \pm 20,1$ & $71,1 \pm 34,4$ & $73,2 \pm 83,4$ \\
\hline Corticeira & $35,0 \pm 19,6$ & $27,1 \pm 14,8$ & $*$ & * \\
\hline Olandi & $11,8 \pm 1,8$ & $14,4 \pm 4,0$ & $*$ & $*$ \\
\hline Licurana & $11,8 \pm 9,7$ & $17,3 \pm 11,5$ & $*$ & $*$ \\
\hline
\end{tabular}

* dados não coletados devido à alta mortalidade das árvores em razão da geada.

$\mathrm{DP}=$ desvio-padrão e Méd. = média. 
Quadro 6 - Teste de Tukey para as espécies ingá e tucaneira, referente à altura total e ao número de folhas das árvores nos diferentes períodos de avaliação, após o plantio, tomados de quatro em quatro meses

Table 6 - Tukey test for the tree species inga and tucaneira, related to total height and number of leaves, under different evaluation periods, after planting

\begin{tabular}{|c|c|c|c|c|}
\hline \multirow{3}{*}{$\begin{array}{l}\text { Período de } \\
\text { Avaliação }\end{array}$} & \multicolumn{4}{|c|}{ Espécie } \\
\hline & \multicolumn{2}{|c|}{ Ingá } & \multicolumn{2}{|c|}{ Tucaneira } \\
\hline & Altura total $(\mathrm{cm})$ & Número de folhas & Altura total $(\mathrm{cm})$ & Número de folhas \\
\hline 5 meses & $60,05 \mathrm{~A}$ & $15,72 \mathrm{~A}$ & $23,55 \mathrm{~A}$ & $25,66 \mathrm{~A}$ \\
\hline 9 meses & $76,26 \mathrm{AB}$ & $38,11 \mathrm{~A}$ & $32,44 \mathrm{~A}$ & $32,88 \mathrm{AB}$ \\
\hline 14 meses & $85,83 \mathrm{~B}$ & $71,44 \mathrm{~A}$ & $35,33 \mathrm{~A}$ & $71,11 \mathrm{AB}$ \\
\hline 18 meses & $121,70 \mathrm{C}$ & $269,00 \mathrm{~B}$ & $56,44 \mathrm{~B}$ & $73,22 \mathrm{~B}$ \\
\hline
\end{tabular}

OBS: Médias seguidas da mesma letra não diferem entre si, na vertical, pelo teste de Tukey, a $5 \%$.

Quadro 7 - Teste de Tukey para as espécies ingá e tucaneira, referente ao incremento de altura total e número de folhas das árvores nos diferentes períodos de avaliação

Table 7 - Tukey test for the trees inga and tucaneira, related to total height increase and number of leaves, under different evaluation periods

\begin{tabular}{|c|c|c|c|c|c|c|}
\hline \multicolumn{7}{|c|}{ Espécie } \\
\hline \multicolumn{3}{|c|}{ Ingá } & \multicolumn{4}{|c|}{ Tucaneira } \\
\hline Inc. & Altura total & $\mathrm{N}^{\mathrm{o}}$ folhas & Inc & Altura total & Inc. & $\mathrm{N}^{\mathrm{o}}$ folhas \\
\hline 2 & $-0,0093 \mathrm{~A}$ & $3,2381 \mathrm{~A}$ & 2 & $0,1845 \mathrm{~A}$ & 3 & $-0,3548 \mathrm{~A}$ \\
\hline 1 & $0,2257 \mathrm{~A}$ & $4,0057 \mathrm{~A}$ & 1 & $0,4021 \mathrm{AB}$ & 1 & $0,0803 \mathrm{~A}$ \\
\hline 3 & 0,7948 B & $27,9809 \mathrm{~B}$ & 3 & $0,7987 \mathrm{~B}$ & 2 & $1,8726 \mathrm{~B}$ \\
\hline
\end{tabular}

OBS: Médias seguidas da mesma letra não diferem entre si, na vertical, pelo teste de Tukey, a $5 \%$.

$\mathrm{O}$ incremento foi colocado em ordem crescente, independentemente do período de avaliação.

De acordo com o Quadro 5, não ocorreram diferenças significativas no incremento da altura total das árvores nos períodos avaliados, tendo ocorrido valores de incremento de altura total negativos devido ao fato de, como a denominação coloca, ter sido medida a altura do fuste, o que significa que a geada danificou os ramos do ápice das plantas, deixando-as com menor altura.

Com relação ao número de folhas, o ingá mostrou um incremento superior ao das demais espécies, mas igual estatisticamente ao do olandi.

Devido à alta mortalidade das espécies corticeira, licurana e olandi, em razão da geada, as leituras posteriores não puderam ser realizadas, bem como as comparações dos incrementos nos demais períodos.

Apesar de as Figuras 1 e 2, bem como os valores do Quadro 4, indicarem um aumento constante na média da altura total e no número de folhas da tucaneira e dos ingás, nos diversos períodos de avaliação ocorreram diferenças significativas apenas nos últimos períodos, conforme mostra o Quadro 6. As outras espécies não puderam ser avaliadas devido à alta taxa de mortalidade após a geada.

No Quadro 7 constata-se que, para os ingás, o incremento 3 foi superior ao dos demais períodos de avaliação, tanto para a altura total quanto para o número de folhas, o que pode ser explicado pelo fato de o incremento 3 envolver as avaliações feitas no verão, período em que os ingás mostraram uma taxa de crescimento maior. A tucaneira tem o comportamento semelhante ao dos ingás, quanto à altura total. No entanto, no que tange ao número de folhas, o incremento 2 foi superior. Este resultado mostra que o fato de a espécie ser caducifólia facilitou a alta taxa de rebrota e o expressivo incremento no número de folhas após um estresse climático de geada.

R. Árvore, Viçosa-MG, v.27, n.5, p.627-634, 2003 
Assim, pode-se admitir que, entre as espécies testadas, os ingás e a tucaneira são as espécies com maior tolerância à geada.

Ao buscar referências bibliográficas sobre as respostas das plantas arbóreas à geada e as alterações microclimáticas em geral, verificou-se uma escassez muito grande de informações bibliográficas, o que gerou dificuldades para avaliar o desempenho e as potencialidades de espécies florestais, diante de eventos climáticos extremos como a geada.

\section{CONCLUSÃO}

As espécies de melhor desempenho, sobrevivência e adaptação foram os ingás, mesmo sob a ocorrência de um estresse climático como a geada. Tal fato indica o alto potencial dos ingás para compor um sistema agroflorestal nas condições edafoclimáticas estudadas.

A tucaneira obteve bom desempenho e adaptação, apresentando alta taxa de sobrevivência e capacidade de rebrota. A exemplo dos ingás, pode-se sugerir esta planta para compor um sistema agroflorestal na região estudada, especialmente porque, por ser uma espécie caducifólia, não produz limitações de radiação solar para o ambiente em períodos de inverno.

Por outro lado as espécies corticeira, olandi e licurana apresentaram alta taxa de mortalidade em função da geada e não parecem ser recomendadas, em princípio, para compor sistema agroflorestal nas condições edafoclimáticas semelhantes às da região estudada.

\section{REFERÊNCIAS BIBLIOGRÁFICAS}

CARVALHO, P. E. R. Espécies florestais brasileiras: recomendações silviculturais, potencialidades e uso da madeira. Brasília: EMBRAPA, CNPF 1994. 640 p.
FRANKE, I. L; MIRANDA, E. M; VALENTIM, J. F. Comportamento de espécies arbóreas de uso múltiplo para Sistemas Agroflorestais no estado do Acre. In: CONGRESSO BRASILEIRO DE SISTEMAS AGROFLORSTAIS, 3., 2000, Manaus. Anais... Manaus: 2000. v. 1. p. 97-100.

LORENZI, H. Árvores Brasileiras: manual de identificação e cultivo de plantas arbóreas nativas do Brasil. 2.ed. Nova Odessa: Plantarum, 1998. 420 p.

MacDICKEN, K. G.; VERGARA, N. T. Agroforestry: classification and management. New York: John Wiley \& Sons, 1990. $382 \mathrm{p}$.

MAGALHÃES, J. A. et al. Avaliação de leguminosas arbóreas e arbustivas de múltiplo propósito em Rondônia. In: CONGRESSO BRASILEIRO DE SISTEMAS AGROFLORESTAIS, 3., 2000, Manaus. Anais... Manaus: 2000. v. 1. p. $42-47$.

PORFÍRIO DA SILVA, V.; MAZUCHOWSKI, J. Z. Sistemas Silvipastoris: paradigma dos pecuaristas para agregação de renda e qualidade. Curitiba: EMATER, 1999. 48 p. (Boletim Técnico, 50)

SÁ, T. D. A. Aspectos climáticos associados a sistemas Agroflorestais: implicações no planejamento e manejo em regiões tropicais. In: CONGRESSO BRASILEIRO SOBRE SISTEMAS AGROFLORESTAIS, 1., 1994, Porto Velho. Anais... Colombo-PR: EMBRAPA/CNPFlorestas, 1994. v. 1. p. 391-431.

SALISBURY, F. B.; ROSS, C. W. Plant physiology. 4.ed. Belmont: Wadworth Publisher, 1994. 389 p.

SILVA, J. G. Avaliação do risco de ocorrência de geadas no Estado de Santa Catarina. 2000. 49 f. Dissertação (Mestrado em Agrometeorologia) - Escola Superior de Agricultura “Luiz de Queiroz”, Piracicaba, 2000.

YOUNG, A. Agroforestry for soil conservation. 3.ed. Nairobi: ICRAF, 1994. 276 p. 